\title{
Dissolved Al in the zonal N Atlantic section of the US GEOTRACES 2010/2011 cruises and the importance of hydrothermal inputs
}

Chris Measures ${ }^{1}$, Mariko Hatta ${ }^{1}$, Jessica Fitzsimmons ${ }^{2}$, Peter Morton ${ }^{3}$

${ }^{1}$ Department of Oceanography, University of Hawaii, Honolulu, HI, 96822

${ }^{2}$ Department of Earth Atmospheric and Planetary Sciences, 77 Mass Ave, Cambridge MA, 02139

3Department of Earth, Ocean and Atmospheric Science, Florida State University, Tallahassee, FL 32306

Accepted version July_1_2014 Deep Sea Research II. 


\begin{abstract}
The distribution of dissolved aluminium determined during GA03, the US GEOTRACES North Atlantic Transects (US GT NAZT) shows large inputs to the basin from three main sources, atmospheric deposition, outflow from the Mediterranean, and inputs from hydrothermal sources along the Mid Atlantic Ridge (MAR).

The partial dissolution of atmospheric aerosols emanating from the Sahara yield high concentrations of dissolved $\mathrm{Al}$ in the surface waters of the basin and are used to estimate the geographical pattern of dust deposition. The Mediterranean outflow delivers a large source of dissolved $\mathrm{Al}$ to the intermediate waters of the eastern basin and its subsequent distribution within the basin can be explained by simple isopycnal mixing with surrounding water masses.

Hydrothermal venting at the Trans-Atlantic Geotraverse (TAG) hydrothermal field in the MAR produces a neutrally buoyant plume that introduces copious quantities of dissolved $\mathrm{Al}$ (with concentrations of up to $40 \mathrm{nM}$ ) to the deeper waters of the North Atlantic that can be seen advecting to the west of the MAR. The concentration of dissolved $\mathrm{Al}$ in the deep waters of the eastern basin of the Atlantic can be accounted for by admixing the MAR Al enriched plume water and Antarctic Bottom Water (AABW) as they pass through the Vema Fracture Zone. The data sets show no evidence for biological remineralisation of dissolved $\mathrm{Al}$ from $\mathrm{Si}$ carrier phases in deep waters.
\end{abstract}




\section{Introduction}

Since the development of the first reliable methodology for determining dissolved $\mathrm{Al}$ in natural waters (Hydes and Liss, 1976) and its application to coastal and then vertical profiles in the Atlantic Ocean, there has been considerable disagreement within the oceanographic community about the major sources and sinks of dissolved $\mathrm{Al}$ to the oceans. Identifying and quantifying sources, sinks and transfer processes of dissolved $\mathrm{Al}$ are fundamental prerequisites to successfully modelling their distributions and using them as tracers of both contemporary, and through sedimentary records, historical oceanic processes, one of the main goals of the GEOTRACES program (GEOTRACES, 2006, Science Plan, Scientific Committee on Oceanic Research, Available online at http://www.geotraces.org/science/scienceplan).

The problem of source and sink identification has been particularly noteworthy in the case of dissolved $\mathrm{Al}$ because as the most abundant metallic element in the Earth's crust and one of the first reactive trace elements for which reliable trace analytical methodology became available (Hydes and Liss, 1976), it received widespread attention from a large number of investigators within the oceanographic community. It became apparent fairly quickly that Al distributions showed large and potentially interesting vertical variations within the water column as well as significant inter- and intra-basin fractionation as seen in the North and South Atlantic (Hydes, 1979, Orians and Bruland, 1985,1986, Measures, 1995).

The relative roles of biotic and geochemical processes on surface $\mathrm{Al}$ distributions have been debated since the first studies of the marine cycle of Al were undertaken. Hydes (1977), as a result of clay dissolution experiments, first suggested that sediment dissolution might be responsible for supplying dissolved $\mathrm{Al}$ to the water column and that biological uptake processes in surface waters might be responsible for depleting $\mathrm{Al}$ values below the concentrations that would be expected 
from clay solubility. This proposed biological mechanism was later expanded to explain the co-variation of $\mathrm{Si}$ and $\mathrm{Al}$ in the Mediterranean, as geochemical cycles of dissolved $\mathrm{Si}$ and $\mathrm{Al}$ could be coupled through diatom uptake in surface waters and remineralisation at depth (Mackenzie et al., 1978). Thus started a debate in the literature as to whether dissolved $\mathrm{Al}$ was under biological or inorganic control. Caschetto and Wollast (1979a), with seasonal data from the Mediterranean, reinforced the biological argument and stated that their distributions were incompatible with precipitation-dissolution mechanisms of clay minerals. Using data from the North Atlantic and Pacific, Hydes (1979) responded by suggesting that surface water Al concentrations were set by deposition and dissolution of atmospheric particles and that passive scavenging removal by the siliceous skeletons of dead organisms whose organic coatings had been degraded was the likely removal mechanism, i.e. not active biological uptake. Additionally, he pointed out that in his Atlantic and Pacific profiles the data did not show a correlation with Si distributions and thus the Mediterranean must be anomalous.

Pore water results from the Mediterranean and North Sea obtained by Caschetto and Wollast (1979b) showed high concentrations of dissolved Si and Al suggesting the sediments could be a deep water source of Al to the water column, but they disputed that simple equilibrium with clays were the driving mechanism. Additional deeper water column data from the Mediterranean and new profiles from the western Atlantic obtained by Stoffyn and Mackenzie (1982) showed that their earlier Al:Si correlations broke down and in some places showed slopes that were the reverse of their earlier ones and the idea that remineralisation of Si phases was responsible for elevated deep water Al concentrations was abandoned. Further work by Hydes (1983) in the eastern Atlantic again showed no relationship with Si cycling but reinforced the concept of eolian deposition as a source to surface waters. This source to surface waters was then supported by additional work by Measures et al. (1984), Moore and Millward (1984), and Orians and Bruland (1985, 1986), who also estimated deep water residence times of dissolved $\mathrm{Al}$ to be of the order 150 years. 
In a series of lab experiments and in profiles from the high energy New England shelf, Moran and Moore (1991) showed that resuspension of sediments played a role in adding dissolved Al to bottom waters. They also showed that passive scavenging of dissolved $\mathrm{Al}$ on dead diatoms was a rapid process and could be modeled in a manner similar to that of dissolved Th (Moran and Moore, 1992). The potential for a hydrothermal source of Al to the oceans was first suggested by Stoffyn and Mackenzie (1982) but was discounted by Hydes et al. (1986) who attributed the deep water maximum in their Mid Atlantic Ridge (MAR) profile at $43^{\circ} \mathrm{N}$ to sedimentary remobilisation within the axial valley of the MAR, as there was no complementary Si enrichment.

Thus, by the early 1990's, the ideas about the sources of Al to the ocean had settled around atmospheric inputs, sedimentary sources, and abiotic removal by scavenging onto particles with some potential for biological transport, but not one exclusively Si based. Since that time the distribution of dissolved $\mathrm{Al}$ in the ocean has been used as a tracer of atmospheric input and its distribution in the deep water has been interpreted as predominantly arising from the subduction and advection of water masses with input from resuspended sediments.

Recently, the biotic influence on $\mathrm{Al}$ and Si cycling has been revisited, based on observed correlations between Si and Al, described by Middag et al. $(2009,2011)$ in the Arctic and North Atlantic Ocean. This uptake and release process has been modeled (van Hulton et al., 2013) using a reversible scavenging model, conceptually similar to that used to reproduce oceanic Th distributions (Bacon and Anderson, 1982). However, the role of hydrothermal vent processes in adding dissolved Al to the deep waters of the Atlantic was specifically excluded, invoking only mechanisms of advection and reversible scavenging by biogenic Si (van Hulton et al., 2013). 
In this manuscript, we present the dissolved $\mathrm{Al}$ data from GA03, the US GEOTRACES 2010 and 2011 cruises that provided quasi-zonal coverage of both the eastern and western basins of the North Atlantic. The transects show very clearly the effect of hydrothermal venting at the Trans-Atlantic Geotraverse (TAG) MidAtlantic Ridge (MAR) vent site in providing copious quantities of dissolved Al to the mid and deep water column of the North Atlantic. They also show that for large areas of the thermocline waters of the Atlantic Ocean, the distribution of dissolved Al can be explained simply by mixing a high Al Mediterranean Outflow Water (MOW) source with a low Al Antarctic Intermediate Water (AAIW) source with no evidence of $\mathrm{Al}$ input to, or removal from, the water column. We will also show that in the eastern North Atlantic, in a region of intense biological activity in surface waters, there is no evidence of dissolved $\mathrm{Al}$ remineralisation in the underlying intense oxygen minimum $\left(\sim 45 \mu \mathrm{M} \mathrm{O} \mathrm{O}_{2}\right)$, nor is there evidence of the surface water Al:Si signal being imprinted on the deep waters through the remobilisation processes as has been proposed elsewhere (Middag et al., 2009, 2011; Van Hulton et al., 2013).

\section{Methods}

\subsection{Sampling methods}

Water samples were collected at approximately two-degree intervals at 32 stations from the $R / V$ Knorr for trace metal determinations during GA03, the U.S. GEOTRACES expeditions, which took place between October 15 and November 4, 2010 (USGT2010: KN199-04: $7^{\circ} \mathrm{N}$ to $17^{\circ} \mathrm{N}$ along $22^{\circ} \mathrm{W}$ ) and between November 6 and December 11, 2011 (USGT2011: KN204-01/02: $70^{\circ} \mathrm{W}$ to $25^{\circ} \mathrm{W}$ ) in the North Atlantic Ocean. Sampling stations are shown in Figure 1. The first cruise (USGT10) started in Lisbon, Portugal and went south along $22^{\circ} \mathrm{W}$, and then from the Mauritanian coast to the Cape Verde Islands (the Mauritanian transect, shown in Figure 1c). The second cruise (USGT11) started from Woods Hole, MA, USA and followed the repeat hydrographic section (Line W) southeast of Cape Cod, to 
Bermuda, and from there continued across the Atlantic ending at a repeat of Station USGT10-10 near the Cape Verde Islands.

Water samples were obtained using the custom-built U.S. GEOTRACES trace metal clean rosette which consists of an epoxy-painted aluminum rosette frame containing $24 \times 12$ L GO-FLO bottles (Cutter and Bruland, 2012). Before deployment and immediately upon recovery, the tops of the GO-FLO bottles were covered with plastic shower-caps, and the bottles were removed from the frame and carried into the GEOTRACES clean van for sub-sampling. The GO-FLO bottles were pressurised to $10 \mathrm{psi}$ using filtered compressed air, and samples were filtered through $0.2 \mu \mathrm{m}$ Acropak filters that had been pre-cleaned by soaking overnight in filtered surface seawater that had been acidified to $\mathrm{pH} 2$ using trace metal clean $\mathrm{HCl}$, after which they were flushed with $5 \mathrm{~L}$ of un-acidified, $0.2 \mu \mathrm{m}$-filtered surface seawater and stored empty in the refrigerator until use. All sub-sampling was undertaken in the clean van using rigorous trace metal protocols. Also, surface samples were collected using an underway towed-fish near-surface pumped seawater system (Johnson et al., 2007), and samples were sequentially filtered in-line at less than 8 psi through $0.45 \mu \mathrm{m}$ Osmonics and then a $0.2 \mu \mathrm{m}$ polycarbonate track etched (PCTE) pleated filter cartridges.

\subsection{Analytical methods}

Seawater samples, collected at the full-depth stations and at demi stations (which only sampled the upper $1500 \mathrm{~m}$ for a more limited number of parameters), were drawn into pre-numbered $125 \mathrm{ml}$ polymethylpentene (PMP) plastic bottles after three rinses and were stored in double plastic bags in the dark at room temperature before the Al determination, which was usually within 12 -36 hours of collection. Prior to analysis, samples for dissolved aluminium (dAl), were acidified by the addition of $125 \mu \mathrm{l}$ sub-boiling distilled $6 \mathrm{~N} \mathrm{HCl}$ (hereinafter $6 \mathrm{~N} \mathrm{HCl}$ ), and then

they were microwaved in groups of 4 for 3 minutes in a $900 \mathrm{~W}$ microwave oven to 
achieve a temperature of $60 \pm 10^{\circ} \mathrm{C}$ to release dissolved $\mathrm{Fe}$, reported by Hatta et al., (this volume). Subsamples were run on board ship within 24 hours of collection using the Flow Injection Analysis (FIA) method of Resing and Measures (1994). The detection limits and the precision of $\mathrm{dAl}$ for each cruise were as follows: $1.02 \mathrm{nM}$ and $1.94 \%$ at $17.58 \mathrm{nM}$ for the USGT10 cruise, and $0.24 \mathrm{nM}$ and $4.8 \%$ at $1.67 \mathrm{nM}$ for the USGT11 cruise.

In order to develop a coherent data set where values between different research groups can be compared, GEOTRACES has designated crossover stations where data can be obtained by different oceanographic groups. The Bermuda time series station S (BATS, Figure 1) is a crossover station for the North Atlantic, and data have been obtained at this station by both the NIOZ group (Royal Netherlands Institute for Sea Research, R. Middag., pers. comm.) in June, 2010 and the UH group in November, 2011.

Although both sets of data appear to be internally consistent and show smooth trends with depth, we note differences in the concentrations obtained by these two labs at this station (NIOZ data not shown as they are currently unpublished). The differences in the upper water column are likely a result of the seasonal difference (June vs November) and the 1.5 year time difference in occupation of this station. Also, the different shape of the profiles at the very bottom of the two profiles appears to be the result of different conditions in the nepheloid layer at the time of sampling, but we do not have access to NIOZ transmissometer data. However, between 974 and $4002 \mathrm{~m}$ where we might expect to see consistency in $\mathrm{Al}$ concentrations over 1.5 years the two sets of data are offset and a cross plot of the data show that they fall on a well constrained line with little scatter $(R=0.993)$ suggesting a simple calibration offset between the methods. This offset varies from the $\mathrm{UH}$ data being $\sim 2 \mathrm{nM}$ higher at $1000 \mathrm{~m} \mathrm{(UH} \mathrm{Al} \sim 14 \mathrm{nM}$ ) to $\sim 4.5 \mathrm{nM}$ higher at $4,000 \mathrm{~m}$ (UH value $\sim 30 \mathrm{nM}$ ). 
Both laboratories use the same chemistry for the analytical determination and are based on the Hydes and Liss (1976) lumogallion method. UH uses the method of Resing and Measures (1994) that was the original adaptation of the Hydes and Liss (1976) method to Flow Injection Analysis, and the NIOZ group uses a slightly modified version of this method that was published later by Brown and Bruland (2008). The main difference of that method from the Resing and Measures (1994) method is the use of a different resin for pre-concentration of the dissolved $\mathrm{Al}$ and the use of distilled water as the carrier instead of seawater.

The differences in concentration between the methods are not likely to be a result of random blanks as both methodologies produce smooth distributions that appear oceanographically consistent. Differences are also not likely to be the result of an un-recognised or overcorrected constant blank in either method as there is not a constant offset between the data sets, which would be expected in the case of a blank/blank correction problem.

We have also eliminated the possibility that this offset is a result of a problem with the UH standards by the following means. Shore-based re-analysis of the UH shipboard Al standards used during the USGT 2010 and USGT 2011 cruises, the original concentrated standards used to produce them and a newly purchased $\mathrm{Al}$ standard (SPEX, Assurance) show maximum differences of $\sim 2.3 \%$ from the expected values, which is close to the precision of the ICP MS measurements (rsd $1 \sigma=1.9 \%)$ used to inter-calibrate them. Thus, we believe that the UH data have been adequately verified by post-cruise ICP-MS calibration of our shipboard standards. Thus at this stage the cause of the offset is still unresolved.

However, regardless of the absolute differences between the reported values, the relative distributions are extremely similar. Thus, differences between the data sets affect absolute values, not the relative processes we describe and model here. They may however eventually provide insight into speciation and fractions of these 
metals in seawater and the importance of retaining shipboard standards and samples for future re-analysis.

\section{Results and discussion}

The cruise track and the general distribution of dissolved $\mathrm{Al}$ in the section are shown in Figs 1-4 produced using Ocean Data View (Schlitzer, 2013).

Our data show that there are three main sources of dissolved Al to the North Atlantic: atmospheric deposition of mineral dust and its partial dissolution in surface waters, inflow of dust-enriched Mediterranean outflow water (MOW) at approx $1200 \mathrm{~m}$ in the eastern basin, and input from the TAG hydrothermal vent site within the axial valley of the Mid Atlantic Ridge at $\sim 3290$ m. Additionally, resuspension of sediments in the energetic western boundary current leaves its mark on the northern source waters that flow around the periphery of the basin. We shall discuss the distribution of dissolved $\mathrm{Al}$ in terms of these sources and their interaction with advective processes in setting the large-scale distribution of dissolved $\mathrm{Al}$ in the North Atlantic. We will also examine the evidence for the hypothesis that vertical transport and remineralisation of dissolved $\mathrm{Al}$ associated with the biological Si cycle is responsible for these vertical distributions.

We will start with the surface waters since this tracks the input of dissolved $\mathrm{Al}$ from mineral dust deposition to the surface ocean and show that as a result of ventilation processes this signal can then penetrate into the oceanic interior. We will then examine the distribution in deeper layers. 


\section{Surface waters}

As described in the introduction, the role that mineral dust deposition and its partial dissolution plays in adding dissolved Al to surface waters has been recognised by many investigators from some of the earliest studies. Building on these observations, Measures and Brown (1996) developed a simple one-box model that used the surface water dissolved Al signal to estimate dust deposition to the waters of the open ocean. This MADCOW model was subsequently validated with extensive data sets showing good agreement between the dissolved Al derived dust deposition estimates and those from independent sources such as land-based aerosol collections reported by Duce et al. (1991) and sediment trap records reported by a variety of workers and summarised by Measures and Vink (2000). Since one of the world's major dust sources, the Sahara, is directly adjacent to the North Atlantic, surface dissolved Al values in this basin are amongst the highest seen in the open ocean.

The dissolved Al data in Figure 2, which are averages of all concentrations determined within the mixed layer (see below for mixed layer definition), shows values that range from $\sim 9-45 \mathrm{nM} \mathrm{Al}$. Overlain on the figure are the speed and direction of surface water flow at $30 \mathrm{~m}$ as recorded by the shipboard ADCP during the time of our station occupation.

Along the USGT11 cruise track, coastal values in the New England shelf are 23-30 nM, with a large increase to $\sim 45 \mathrm{nM}$ coincident with the cruise track crossing into the Gulf Stream at USGT11-03 as shown in the overlain ADCP data (Figure 2). Higher values in the Gulf Stream are consistent with the Caribbean source of these waters, which is directly under the main plume of the Saharan dust (Husar et al., 1997). The values in the western edge of the Sargasso are somewhat lower than the Gulf Stream at 32-36 $\mathrm{nM}$ but build towards the centre of the gyre reaching a maximum of $\sim 46 \mathrm{nM}$ between 53 and $47^{\circ} \mathrm{W}$. Values then drop rapidly towards the east, particularly around $36^{\circ} \mathrm{W}$ (USGT11-20) where the effect of the southward 
flowing Canary Current can be seen in the ADCP data. Values continue to drop reaching $19 \mathrm{nM}$ at the Tenatso station USGT11-24. The equivalent occupation of this same station in 2010 (USGT10-12) showed somewhat lower surface water concentrations of $\sim 15 \mathrm{nM} \mathrm{Al}$. Continuation of the section towards the Mauritanian coast using the USGT10 data shows surface values increasing again as the ship's track encounters the coastal current and the upwelling regime directly under the Saharan plume. To the north along the USGT10 cruise track, Al concentrations decrease significantly as the track moves out of the Saharan plume with values dropping to $\sim 9-11 \mathrm{nM}$ at USGT10-1\&2. A small region of higher values (20-23 nM) is seen at USGT10-5\&6 which are situated to the west and downwind of the Canary Islands. The USGT10 cruise track overlaps part of the meridional CLIVAR A16N section (occupied in 2003) along $\sim 25^{\circ} \mathrm{W}$ between $\sim 31$ to $17^{\circ} \mathrm{N}$ (Measures et al., 2008). Despite the $\sim 7-8$ year gap in sampling times, very similar surface $\mathrm{Al}$ values (11-24 $\mathrm{nM}$ ) are seen in this region, including an elevated region to the west of the Canary Islands, where values of 17-24 nM Al were also observed in 2003 (Measures et al., 2008).

The pattern of higher dissolved $\mathrm{Al}$ values seen in the central and western part of the sub-tropical gyre is similar to that seen in earlier surface water Al data sets reported by a variety of authors between 30 and $40^{\circ} \mathrm{N}$ and summarised by Measures et al. (2008). Thus, this pattern appears to be a relatively steady-state phenomenon for $\mathrm{Al}$ and is also similar to the geographical pattern of enrichment seen for several other dust-derived elements by GA03 cruise participants (Hatta et al., this volume). 


\section{Dust deposition estimates}

The mixed layer dissolved Al values can be transformed into dust deposition estimates using the MADCOW model (Measures and Brown, 1996) which is a simple one box model that assumes that the existing dissolved concentration of $\mathrm{Al}$ in the mixed layer of the ocean is at a steady state between the competing process of partial dissolution of $\mathrm{Al}$ from mineral dust added to the surface ocean from the atmosphere, and scavenging removal onto particles exported from that surface layer. Implicit in this assumption is that the only source of Al to the surface ocean is from partial dissolution of mineral dust. In its simplest form the MADCOW model uses a fixed mixed layer depth of $30 \mathrm{~m}$, a uniform surface water residence time of 5 years, and assumes a solubility of 3.3\%. In its application to this data set, we have adjusted these parameters to use the actual mixed layer depth we observed during our sections, which we define using a criterion of a $0.125 \mathrm{~kg} \mathrm{~m}^{-3}$ difference in density between the surface samples and the bottom of the mixed layer (Hatta et al., this issue). In addition to the density criterion, the temperature and salinity profiles were inspected at each station for uniformity within this layer, and if they were not uniform, the depth of any perturbation in the profile was chosen as the base of the mixed layer. In addition we also calculate dust deposition along the 2003 CLIVAR A16N section to compare with the GA03 data.

The MADCOW calculated dust deposition along the USGT10 and USGT11 cruise track ranges from $3.61 \mathrm{~g} \mathrm{~m}^{-2} \mathrm{yr}^{-1}$ at USGT11-03 in the Gulf Stream to $0.91 \mathrm{~g} \mathrm{~m}^{-}$ ${ }^{2} \mathrm{yr}^{-1}$ at USGT10-02 off the coast of Portugal, with a broad area of deposition $>3 \mathrm{~g} \mathrm{~m}^{-2}$ $\mathrm{yr}^{-1}$ in the centre of the subtropical gyre (Figure 3). While these values are within the ranges that have been reported for offshore waters in the tropical Atlantic (Duce et al., 1991), the spatial pattern they show is counter-intuitive, with higher values in the western and central basins despite the eastern Saharan source. Although deposition values increase along the track towards the African coast, reaching $\sim 3 \mathrm{~g}$ $\mathrm{m}^{-2} \mathrm{yr}^{-1}$ at USGT10-09, these values are lower than the geographical deposition estimates of Duce et al. (1991), the pattern from the shipboard dust collections 
(Shelley et al., this volume), and the relative abundance of particulate lithogenic material sampled from the water column with in situ pumps (Ohnemus et al., this volume). It is thus important to understand the underlying causes of these differences.

The first thing to note is that there are significant differences in the time scale that these signals represent. Shipboard aerosol sampling represents atmospheric loading during the cruise period, and the load of suspended particulate matter in the water column probably represents deposition to the ocean on a time scale of weeks to at most a few months. In contrast, dissolved $\mathrm{Al}$, as a result of its residence time in surface waters (Jickells et al., 1994), is assumed to represent a moving average of dust input over an $\sim 5$ year period (Measures and Brown, 1996). It is this much longer time scale that is the root cause of the difference between the MADCOW and these other dust deposition estimates.

In the active upwelling region off Mauritania, the steady state assumption of the MADCOW model is not met because sub-surface water is providing 4-8 $\mathrm{nM}$ additional, non-aerosol $\mathrm{Al}$ to surface waters, thus leading to a $0.3-0.6 \mathrm{~g} \mathrm{~m}^{-2} \mathrm{yr}^{-1}$ overestimate of dust deposition in this area. However, competing with this overestimation is the likely underestimation of dissolved $\mathrm{Al}$ from dust input, since the upwelled water has not been at the surface for 5 years and therefore is not yet at steady state with the input. Since we do not know how long the water has been at the surface, we are not able to correct for this underestimate. Nevertheless, comparison with shipboard results and the Duce et al. (1991) estimates suggests that on balance the MADCOW approach is underestimating deposition in this area.

Similarly the assumed 5 year residence time of dissolved $\mathrm{Al}$ means that in advective regions the surface water will have moved considerable distances during this period (up to $3000 \mathrm{~km}$ at a velocity of $10 \mathrm{~cm} \mathrm{~s}^{-1}$ ). This is the underlying cause of the decreasing deposition estimates seen in the eastern part of the section between USGT11-16 \& 24. This region corresponds to the ship's track crossing into the 
southward flowing Canary Current (Figure 2) that is bringing waters from the north, outside the main Saharan plume, and thus have been subject to less dust deposition.

Thus deposition values calculated from dissolved Al reflect an $\sim 5$-year running average of dust input into each square metre of surface water as it moves, not to a geographically static region in the manner of dust deposition maps derived from atmospheric data. Therefore, in regions affected by significant advection of surface water, this distribution will be different from that obtained from atmospheric sampling at fixed stations or from modelling efforts. While each estimate has its particular value in quantifying atmospheric processes, from an oceanographic perspective the imprint of dissolved $\mathrm{Al}$ in surface water is the most relevant parameter for understanding oceanic biogeochemical processes since it tracks the addition of dissolved materials to the surface water from dust deposition.

\section{Sub Tropical Mode Water}

In the subsurface waters of the western section between stations USGT11-08 \&15, (Figure 4, panel A), a region of enhanced Al, generally $>30 \mathrm{nM}$, can be seen around $300 \mathrm{~m}$ corresponding to the $18^{\circ}$ Sub-Tropical Mode Water (Worthington, 1959). This high salinity, high dissolved $O_{2}$ water mass centred at $\gamma^{\mathrm{n}}=26.5$, which can also be identified by a local minima in the potential vorticity, forms in the late winter in the recirculation regime near the Gulf Stream (Talley et al., 2011), and through subduction carries the properties of the surface water into the interior of the Atlantic. Thus, the enhanced $\mathrm{Al}$ values seen in this water mass, which have been observed before in isolated stations (Measures et al., 1986) reflect the late winter surface water dissolved $\mathrm{Al}$ values, which are enhanced as a result of mineral dust deposition to this region. Diluted remnants of this subducted water mass can be seen stretching to the east of the MAR at the latitude of the USGT11 section to USGT10-5\&6 (Figure 4, panel B) where a somewhat attenuated maximum in dissolved $\mathrm{Al}$ of $\sim 27 \mathrm{nM}$ can be seen associated with $\mathrm{T}, \mathrm{S}$ and neutral density 
parameters that are very similar to those in the west. Although there is an eastern basin counterpart to the western basin $18^{\circ}$ STMW, the Madeira Mode water (Siedler et al., 1987), which forms at the surface around $35^{\circ} \mathrm{N}$ south of the Azores Current front (Talley et al., 2011), we discount that this is the source of the eastern maxima for two reasons. The first is that the residence time of the Madeira mode water is $\sim 9$ months (Talley et al., 2011) and thus we would expect it to be almost completely dissipated given the $\sim 8$ month elapsed time between its late March formation time and our November sampling. Secondly, the surface water Al concentrations that we and others have observed in the area to the NW of Madeira where this water mass forms are much lower than the values we see in the STMW in this section (Siedler et al., 1987).

\section{The Mediterranean Outflow waters (MOW) and Antarctic Intermediate Water} (AAIW)

On the eastern boundary of the Atlantic in the N-S transect of the USGT10 cruise (Figure 4, panel C), the dissolved $\mathrm{Al}$ data show a clear maximum at $\sim 1200 \mathrm{~m}$ at stations USGT10-01 to 03 that is coincident with high salinity (contoured on top of the Al distribution) MOW entering the Atlantic. This water mass, which is a combination of Western Mediterranean Deep Water and Levantine Intermediate Water, exits through the shallowest, $\sim 290 \mathrm{~m}$ deep Camarinal Sill at the Strait of Gibraltar and then sinks down the Atlantic slope, constantly entraining surrounding water to form a neutrally buoyant plume at $\gamma^{\mathrm{n}}=27.5-27.9 \mathrm{~kg} \mathrm{~m}^{-3}$, centred at $\sim 27.7$ $\mathrm{kg} \mathrm{m}^{-3}$. This plume then spreads out along this isopycnal over large areas of the North Atlantic at a depth of approximately $1200 \mathrm{~m}$. At our closest station to the outflow, USGT10-01, the maximum dissolved $\mathrm{Al}$ is $48 \mathrm{nM}$ at a salinity of 36.503 and $1186 \mathrm{~m}$ depth. A previous determination of the dissolved $\mathrm{Al}$ in the MOW outflow at the strait of Gibraltar (Measures and Edmond, 1988) reported values of $\sim 71 \mathrm{nM} \mathrm{Al}$ at a salinity of $\sim 38.1$ at $\sim 400 \mathrm{~m}$. Since USGT10-01 is some $\sim 400 \mathrm{~km}$ to the northwest of that 1986 station, we expect a more diluted signal of the outflow water 
as a result of the progressive entrainment of lower $\mathrm{Al}$ water into the MOW as it sinks to its neutral density surface at $\sim 1200 \mathrm{~m}$.

By station USGT10-05 at a latitude of $31^{\circ} \mathrm{N}$, the salinity and $\mathrm{Al}$ maximum have been eroded from the vertical profiles at this depth as the MOW is now opposed by, and mixing with, the northward flowing low salinity, low Al AAIW on this neutral density layer. The AAIW, which forms in the South Atlantic between 45 and $50^{\circ} \mathrm{S}$, has a salinity of $\sim 33.8$ and a potential temperature of $2.2^{\circ} \mathrm{C}$ at its point of origin. By the time it reaches the eastern side of the $\mathrm{N}$ Atlantic its core properties have been mixed with surrounding waters and the salinity minima values at USGT10-9\&10 of 34.91-34.94 and $\theta=6.0-6.5$ are seen at depths of $800-973 \mathrm{~m}$. The influence of the AAIW diminishes rapidly to the north in the USGT10 section with the salinity minimum disappearing by USGT10-06 at $27^{\circ} \mathrm{N}$. The salinity minimum of the AAIW can be traced along the $\gamma^{\mathrm{n}}=27.7$ surface as it erodes westward across the basin in the USGT11 section, disappearing completely by USGT11-11 at $\sim 60^{\circ} \mathrm{W}$, where southward flowing Irminger Sea Water (ISW) and upper Labrador Sea water take its place in this part of the water column. The AAIW is formed in the South Atlantic where dust deposition levels are low (Duce et al., 1991; Vink and Measures, 2001), and consequently the dissolved Al values of the AAIW in its formation region are also low. Dissolved Al data in the AAIW sampled in the Cape and Angola basins of the eastern S Atlantic (Measures, 1995) show Al values of $\sim 2-3 \mathrm{nM}$ at salinities of 34.32 and 34.48 .

A plot of all the Al data in the $\gamma^{\mathrm{n}} 27.5-27.9$ density range from all the stations of USGT10 and all USGT11 station to the west of USGT11-11 (Figure 5), shows an extremely good correlation $(\mathrm{R}=0.98$; $\mathrm{n}=83$ ) between the high salinity, high $\mathrm{Al}$ of the MOW and the low salinity, low Al water of the AAIW. If this correlation is extrapolated to a salinity value of 38.088, it predicts an Al value of $80.7 \mathrm{nM}$, slightly higher than the $72 \mathrm{nM}$ value measured in the MOW in 1986 (Measures and Edmond, 1988), which, as noted above, was not at the neutral density depth of the MOW 
plume, and thus might not be expected to fall on this mixing series. At the lower end, the predicted intercept of $\sim 1 \mathrm{nM}$ at a salinity of 34.4, is close to the $1995 \mathrm{Al}$ value determined in the AAIW in the Cape Basin (Measures, 1995). The fact that these points fall so clearly on this mixing line with only minimal scatter we take as strong evidence that the distribution of dissolved $\mathrm{Al}$ in these waters is a result of a simple linear mixing between the MOW and AAIW end members. This result also reinforces the concept that at least along this density surface across the entire $\mathrm{N}$ Atlantic Basin there is no evidence for addition or removal of dissolved $\mathrm{Al}$ from the water column. In other words, the mixing process in this region of high atmospheric deposition to the surface waters and copious vertical transport by biological

processes, is conservative, with no evidence of a remineralised Al signal. This conclusion is similar to that first reported by Measures and Edmond in 1990 based on the relationship between $\mathrm{Al}$ and salinity and $\mathrm{Al}$ and $\mathrm{Si}$ in the components of the lower NADW in the western basin of the North Atlantic when compared to values in the South Atlantic (Measures and Edmond, 1990)

\section{The waters of the New England shelf: USGT11-01-USGT11-11}

As described above, there is a distinct change in water masses at the boundary between USGT11-11 and USGT11-12 (Figure 4); however, the nature of the changes is more visible at the full depth station USGT11-10. At that station from $\sim 950 \mathrm{~m}-1800 \mathrm{~m}, \gamma^{\mathrm{n}}=27.51-27.95$, CFC levels are elevated, indicating the presence of recently ventilated waters (W. Smethie pers. comm.). Additionally, the $\theta$, salinity and silicate values indicate this water mass originated in the Labrador Sea. Dissolved Al values, in contrast, drop across this boundary, falling from 17-19 $\mathrm{nM}$ in the offshore gyre stations to 13-15 $\mathrm{nM}$ in the LSW and the shelf water stations. Although these values in the core of the Labrador Sea Water (LSW) USGT11-10 are relatively low compared to the gyre background, they are actually higher than the $\sim 7 \mathrm{nM}$ values reported in the filtered samples of LSW near its source at $55^{\circ} \mathrm{N}$ by Hall and Measures (1998). Here, we do see evidence of the addition of dissolved $\mathrm{Al}$ along the advective 
flow path of the LSW from its formation region in the Labrador Sea to the New England coast. This addition is consistent with the experimental and observational evidence presented by Moran and Moore (1991), who showed increased dissolved $\mathrm{Al}$ values in the near bottom waters off the Grand Banks of Nova Scotia, which they ascribed to inputs from resuspended sediments. It is also consistent with the concentration gradients seen in the various components of dissolved and colloidal Fe and dissolved Mn concentrations (Fitzsimmons et al., this issue; Hatta et. al., this issue). Thus, where we do see addition of dissolved Al to the water column, it is associated with sedimentary input along this advective flow path that follows the contours of the North American continental shelf in a region of extremely high resuspended material (Biscaye and Ettreim, 1977).

\section{Hydrothermal inputs and their dispersal}

One of the most striking features of the data set is the clear source of dissolved $\mathrm{Al}$ at the MAR station USGT11-16 located close to the $\sim 3620-3675 \mathrm{~m}$ deep TAG hydrothermal vent field (Figure 4C). At this station, high resolution sampling in the bottom $600 \mathrm{~m}$ was deliberately targeted to intersect the neutrally buoyant hydrothermal plume from this vent site. In addition to the normal sampling from the U.S. GEOTRACES trace metal clean rosette, we obtained additional samples from the regular hydrography rosette supplied by the Scripps Institution of Oceanography Ocean Data Facility (SIO ODF) that used standard 30 L Niskin bottles with internal springs to collect samples for non-contamination prone elements. Although there is clearly a danger of Al contamination of the samples from this system, our data (Figure 6) show that the elevated values seen by both sampling systems were very similar. Dissolved Al values in the plume reach 39-53 nM in the water column immediately above the hydrothermal vent site (depth range 3000$3595 \mathrm{~m} ; \gamma^{\mathrm{n}}$ range 28.06-28.08). These values are comparable to the 40-48 nM values reported for the TAG hydrothermal plume by Lunel et al. (1990) at an almost

identical depth. Our deepest sample at $3587 \mathrm{~m}$ is some $87 \mathrm{~m}$ above the axial valley floor, which at this location is at $3674 \mathrm{~m}$. While there are no reported 
measurements of dissolved $\mathrm{Al}$ in the hydrothermal end-member at the TAG vent site, there are other vents within the MAR that have been sampled and where both $\mathrm{Al}$ and Si were determined. Those values (Table 1) show end members (high temperature, undiluted vent fluid) that range from 1.8-5.3 $\mu \mathrm{M} \mathrm{Al}$. Although this concentration range is large, the Si:Al ratio in these vents and also one from the $21^{\circ} \mathrm{N}$ vent site are fairly constant at $\sim 3,500 \pm 480: 1$ (Si:Al mole:mole). Thus, using the determined Si end member value at TAG of 19-22 mM (Campbell et al., 1988; Rudnicki and Elderfield, 1992; Edmond et al., 1995), we can calculate a likely end member of $\sim 5.4-6.3 \mu \mathrm{M} \mathrm{Al}$. ${ }^{3} \mathrm{He}$ concentrations determined in the neutrally buoyant plume at this station (W. Jenkins pers. com.), when compared to previously reported end member concentrations for TAG vent fluids (Rudnicki and Elderfield, 1992), imply an $\sim 50,000$-fold dilution of the vent fluid by surrounding seawater leading to the formation of the neutrally buoyant plume. Thus, with a proposed vent end member of $\sim 6 \mu \mathrm{M} \mathrm{Al}$ we would expect an undetectable enrichment of $\sim 0.1 \mathrm{nM}$ $\mathrm{Al}$ in the plume over ambient values. Even if our end member estimate was low by a factor of 10 , the neutrally buoyant plume enrichment would only be $\sim 1 \mathrm{nM}$, still barely detectable. In contrast, we see much higher enrichment values in the plume ( 11-19 nM above background) when compared to stations on either side of the MAR.

Exactly why the TAG neutrally buoyant plume is so much more enriched in Al than would be predicted from its likely end member is beyond the scope of this manuscript. However, this phenomenon was previously observed by Lunel et al. (1990), who also observed very high concentrations of dissolved Al (up to $62 \mathrm{nM}$ ) in the very bottom waters within $140 \mathrm{~m}$ of the TAG site. From their modelling of the entrainment process, they suggested that the entrainment of these Al-enriched near bottom waters could account for $\sim 50-70 \%$ of the $\mathrm{Al}$ anomaly observed in the plume. Our deepest samples show $\mathrm{Al}$ concentrations decreasing below the neutral density plume, but our sampling does not go deep enough to sample the very enriched bottom waters reported by Lunel et al., (1990). 
The depth of the axial rift valley of the MAR is such that the neutrally buoyant plume at 3,200 $\mathrm{m}$ is constrained within the axial graben of the MAR, and thus the hydrothermal signals are to some degree trapped within this feature, perhaps allowing a much larger signal to develop than would otherwise be possible. Circulation and plume dispersal have been described in detail at the more northerly Rainbow Ridge (German et al., 1998), and the effects of tidal cycles on the plume at the TAG site have been described by Rudnicki et al. (1994). From these studies and others using naturally occurring radionuclides, German et al. (1991) have suggested that a large degree of mixing and re-entrainment of older plumes and reemplacement of particulate material that has precipitated from the neutrally buoyant plume can occur within these systems as the vertical density gradients within the graben are very weak. Thus, it might appear that the physical setting of the vent sites within an enclosed axial valley on this slow spreading ridge is what leads to this $\mathrm{Al}$ enrichment.

Despite this plume trapping, the effects of the hydrothermal input are clearly visible in the water column to the west of the MAR in the nearest deep station (USGT11-14), where Al values of 31-33 nM can be seen from $3000 \mathrm{~m}$ to the bottom at $4230 \mathrm{~m}$ in the density range $\gamma^{\mathrm{n}} 28.066-28.125$ (Figure 6, blue, and Figure 4). In addition to showing the known general westward flow at this depth (there is no equivalent enrichment at station USGT11-18 to the east of the MAR, Figure 6, purple), this also indicates that the enriched Al signal must be able to exit the axial valley of the MAR. However, it is important to note that the elevated values that we see to the west of the MAR are not necessarily from the TAG vent site. The frequency of venting along the MAR at this latitude ( 1 vent every $130 \mathrm{~km}$, German and Parson 1998), when coupled with the numerous transverse faults and the progressive deepening of the axial ridge to the south (Rona, 1977) provide ample opportunities for $\mathrm{Al}$ enriched seawater from a variety of such vents along the MAR to enter the deep waters at progressively deeper depths. This is particularly 
relevant when (below) we consider the potential for the Romanche and Vema Fracture Zones to be the likely source of enriched $\mathrm{Al}$ we see in the deeper waters of the eastern basin.

Thus, it is clear that hydrothermal processes in the Atlantic are significant contributors to dissolved $\mathrm{Al}$ in the deeper water column, in both the western basin and the eastern basin, as we elaborate below. It is noteworthy that this source was specifically excluded in the Atlantic Ocean Al model of van Hulten et al. (2013).

\section{The deep waters of the eastern basin}

The origin of the elevated dissolved $\mathrm{Al}$ in the eastern basin is of particular interest since the boundary currents in this basin are much weaker than those seen in the western basin, and thus it is unlikely that resuspension of sediments can be the source. Instead we propose that the same Al plumes from hydrothermal venting that are elevating the $\mathrm{Al}$ in the deep waters of the western basin are also adding material to the eastern basin via mixing of these hydrothermally-influenced western basin water in the fracture zones.

The principal connections between the western and eastern basins of the tropical Atlantic occur through the 4,000 m deep Romanche and 4,700 m deep Vema Fracture Zones (FZ) that cut through the MAR ridge at $1^{\circ}$ and $12^{\circ} \mathrm{N}$, respectively (Heezen et al., 1964). These passageways provide a conduit for waters from the western basin (AABW and lower NADW) to ventilate this basin. A detailed set of transects in this region led McCartney et al. (1991) to suggest that it is the Vema FZ that is principally supplying the water that is ventilating the NE Atlantic Basin $(\sim 2$ Sv) and that the more southerly Romanche FZ situated at the Equator only supplies water to the basins south of the Sierra Leone Rise at $\sim 8^{\circ} \mathrm{N}$.

The deep passageways $(\sim 5,200 \mathrm{~m})$ of the Vema FZ on the western side of the MAR allow the low temperature, high $\mathrm{Si}$, northward flowing AABW to penetrate 
eastward across the MAR until they encounter the primary sill at $\sim 41^{\circ} \mathrm{W}, 4,650 \mathrm{~m}$ where mixing with the overlying lower NADW occurs. This process then repeats at the secondary sill, 4,700 $\mathrm{m}$ (McCartney et al., 1991) further east at $\sim 39^{\circ} \mathrm{W}$, and both processes result in a jump in the bottom water temperatures and a reduction of $\mathrm{Si}$ in the bottom waters as the high $\mathrm{Si}$, low $\mathrm{T}$, AABW is mixed with the low $\mathrm{Si}$, higher $\mathrm{T}$, lower NADW. In a similar manner, we propose that low Al AABW from the western basin such as we see at the bottom of USGT11-12 (Figure 4), is mixed with Al enriched waters that have escaped the MAR axial valley as seen at the bottom of USGT11-14. These are mixed within the Vema FZ and delivered to the eastern basin, resulting in elevated $\mathrm{Al}$ values such as at USGT11-20.

While we do not have samples at the entrances and exits to Vema FZ, we can show the general feasibility of this process using the $\mathrm{Si}$ and $\mathrm{Al}$ data from our full depth stations on either side of the MAR and using our deepest sampling in the AABW to provide the western basin end member at USGT11-12. The values used are shown in Table 2 and a simple cross plot (Figure 7) shows quite remarkably that such a mixture is a feasible solution to the source of the eastern basin Al. Although the deep water $\mathrm{Al}$ value at station 20 is clearly above this mixing line it is quite feasible that additional high Al water from the axial valley of the MAR could contribute dissolved Al to the mixture. Confirmation of this source would require a much higher resolution sampling in the region of this $\mathrm{FZ}$ than is possible in the GEOTRACES project.

We note that Klinkhammer et al. (1985) observed a plume of elevated Mn concentrations, indicating hydrothermal processes in the axial valley of the MAR at $11^{\circ} \mathrm{N}$ very close to the Vema FZ, and that Fitzsimmons et al. (2013) also suggest a source of hydrothermal Fe to the eastern N Atlantic basin. Thus, it is very probable that there would be additional sources of dissolved $\mathrm{Al}$ in this region that could add to the waters flowing through the Vema FZ.

\section{The waters of the Mauritanian Shelf}


The intense oxygen minimum at USGT10-09 (Figure 8) where values as low as $45 \mathrm{uM} \mathrm{O}_{2}$ can be seen stretching to USGT10-12 in an attenuated form along $\gamma^{\mathrm{n}}=$ 27.1 is a result of the high productivity from upwelling along the NW African coast. The upper part of the dissolved Al minimum in this region (which is above the $\gamma^{\mathrm{n}}$ layer of the AAIW mixing series) coincides very closely with this $\mathrm{O}_{2}$ minimum. This indicates that in this intense depth range of biological remobilisation, under surface waters which receive large fluxes of $\mathrm{Al}$ from mineral dust deposition, there is no evidence of the release of dissolved $\mathrm{Al}$ to the water column through the remineralisation process. Furthermore in the deeper waters of these stations where high Si levels from benthic remobilisation are evident, the $\mathrm{Si} / \mathrm{Al}$ ratio is completely different from that of the surface waters, in contrast to that which would be expected from a biological remineralisation signal (Figure 8). Thus, this region which maintains one of the highest biological exports and also receives copious quantities of dissolved $\mathrm{Al}$ to the surface waters, shows quite distinctly that there is neither $\mathrm{Al}$ remineralisation associated with water column processes nor evidence for this process at the sediment water interface. These observations clearly call in to question the applicability of the van Hulten et al., 2013 model of these processes.

\section{Conclusions}

The dissolved Al distributions that we see in the zonal transect of the North Atlantic can be interpreted as resulting from a series of inputs and their redistribution by physical processes. At the surface of the ocean, partial dissolution of atmospherically-transported mineral dust labels all the surface waters of the North Atlantic to varying degrees, reflecting the amount of dust deposition they receive. This signal is carried into the sub-tropical mode water by the physical subduction of surface waters in late winter. A large input of $\mathrm{Al}$ enriched water from the Mediterranean outflow (that also originated from high dust deposition within 
that basin) can be seen mixing isopycnally with AAIW, with no evidence of dissolved $\mathrm{Al}$ addition or removal. Inputs of dissolved $\mathrm{Al}$ from resuspended sediments or their associated pore waters are evident along the advective flow path of the ULSW as it traverses the North American shelf. A significant dissolved $\mathrm{Al}$ input associated with the neutrally buoyant hydrothermal plume at the TAG MAR vent site can be seen escaping the MAR and labelling the deep waters of the western basin. The $\mathrm{Al}$ labelled western basin deep water when mixed with AABW is shown to be capable of producing the elevated values of dissolved $\mathrm{Al}$ seen in eastern basin waters. In the highly productive upwelling zone of the Mauritanian shelf, we see strong evidence of Al depletion by biological scavenging, but no evidence of its regeneration in either the oxygen minimum or at the bottom of the water column where $\mathrm{Si}$ is remobilised.

\section{Acknowledgements}

We would particularly like to thank the organizers of the cruises, Ed Boyle, Bill Jenkins, Greg Cutter and Bob Anderson and all the shipboard participants for the hard work they all contributed to make a success of the first US GEOTRACES section cruises. We would also like to acknowledge the support provided by the Scripps Ocean Data Facility (SIO ODF, Mary Johnson, Rob Palomares, Courtney Schatzman and Melissa Miller) in providing the high quality hydrographic parameters and shipboard data management. We would also like to acknowledge the three anonymous reviewers whose positive comments helped improve the readability of the manuscript. This work was supported by NSF OCE-0928741 and OCE-1137812 to CIM. This is SOEST contribution number 9168. 


\section{References}

Bacon, M.P., and R.F. Anderson, 1982. Distribution of thorium isotopes between dissolved and particulate forms in the deep sea, J. Geophys. Res. 87, 2045-2056.

Biscaye, P.E., and S. L. Eittreim, 1977. Suspended particulate loads and transports in the nepheloid layer of the abyssal Atlantic Ocean, Marine Geology, 23,155-172.

Brown, M.T. and K. W. Bruland, 2008. An improved flow-injection analysis method for the determination of dissolved aluminum in seawater, Limnol. Oceanogr. Methods, 6, 87-95.

Campbell, A.C., M.R. Palmer, G.P. Klinkhammer, T.S. Bowers, J.M. Edmond, J.R. Lawrence, J.F. Casey, G. Thompson, S. Humphris, P. Rona, J.A. Karson, 1988. Chemistry of Hot Springs on the Mi-Atlantic Ridge, Nature, 335, 514-519.

Caschetto, S. and R. Wollast, 1979a. Vertical distribution of dissolved Aluminium in the Mediterranean Sea, Marine Chemistry, 7, 141-155.

Caschetto, S. and R. Wollast, 1979b. Dissolved aluminium in interstitial water of recent marine sediments, Geochim. Cosmochim. Acta, 43, 425-428.

Cutter, G.A., and K.W. Bruland, 2012. Rapid and noncontaminating sampling system for trace elements in global ocean surveys. Limnol. Oceanogr. Methods 10, 425-436.

Duce, R.A., and 21 others, 1991. The atmospheric input of trace species to the world ocean. Global Biogeochemical Cycles, 5, 193-259.

Edmond, J.M., A.C. Campbell, M.R. Palmer, G.P Klinkhammer, C.R. German, H.N. Edmonds, H. Elderfield, G. Thompson, and P. Rona, 1995. Time series studies of vent fluids from the TAG and MARK sites (1986, 1990) Mid-Atlantic Ridge: a new solution chemistry model and a mechanism for $\mathrm{Cu} / \mathrm{Zn}$ zonation in massive sulphide orebodies, Hydrothermal Vents and Processes (L.M. Parson, C.L. Walker, and D.R. Dixon, eds.), Geological Society Special Publication No. 87, 77-86.

Fitzsimmons, Jessica N., Ruifeng Zhang, Edward A. Boyle, 2013. Dissolved iron in the tropical North Atlantic Ocean, Marine Chemistry 15487-99.

German, C.R., A.P. Fleer, M.P. Bacon, and J.M. Edmond, 1991. Hydrothermal scavenging at the Mid-Atlantic Ridge: radionuclide distributions. Earth and Planetary Science Letters, 105, 170-181.

German, C.R., K.J. Richards, M.D. Rudnicki, M.M. Lam, J.L. Charlou, and the FLAME Scientific Party, 1998. Topographic control of a dispersing hydrothermal plume, 
Earth and Planetary Science Letters, 156, 267-273.

German C.R. and L.M. Parson, 1998. Distributions of hydrothermal activity along the Mid-Atlantic Ridge: interplay of magmatic and tectonic controls, Earth and Planetary Science Letters 160, 327-341.

Hall, I., and C.I. Measures, 1998. The distribution of $\mathrm{Al}$ in the IOC stations of the North Atlantic and Norwegian Sea between $52^{\circ}$ and $65^{\circ}$ North, Marine Chemistry, $61,69-85$.

Heezen B. C., R. D. Gerard and M. Tharp, 1964. The Vema Fracture-Zone in the equatorial Atlantic, Journal of Geophysical Research, 69, 733-139.

Hydes, D.J., and P.S. Liss, 1976. Flourimetric method for determination of low concentrations of dissolved Aluminium in natural waters. Analyst 101, 922-931.

Hydes, D.J., 1977. Dissolved aluminium concentration in sea water, Nature 268, 136 $-137$.

Hydes, D.J., 1979. Aluminum in Seawater: Control by Inorganic Processes, Science, $205,1260-1262$.

Hydes, D. J., 1983. Distribution of aluminium in waters of the North East Atlantic $25^{\mathbf{0}} \mathrm{N}$ to $35^{\circ} \mathrm{N}$, Geochim. Cosmochim. Acta, 47, 967-973.

Hydes, D.J., P.J. Statham and J.D. Burton, 1986. A vertical profile of dissolved trace metals $\left(\mathrm{Al}, \mathrm{Cd}, \mathrm{Cu}, \mathrm{Mn}, \mathrm{Ni}\right.$ ) over the median valley of the Mid Atlantic Ridge, $43^{\circ} \mathrm{N}$ : implications for hydrothermal activity, Science of the Total Environment, 49,133145.

van Hulten, M.M.P., A. Sterl, A. Tagliabue, J.-C. Dutay, M. Gehlen, H.J.W. de Baar, and R. Middag, 2013. Aluminium in an ocean general circulation model compared with the West Atlantic Geotraces cruises, Journal of Marine Systems, 126, 3-23.

Husar, R.B., J.M. Prospero, and L.L. Stowe, 1997. Characterization of tropospheric aerosols over the oceans with the NOAA advanced very high resolution radiometer optical thickness operational product, J. Geophys. Res., 102 16,889-16,909. (96JD04009).

Jickells, T. D., T. Church, A. Veron, and R. Arimoto, 1994. Atmospheric inputs of manganese and aluminum to the Sargasso Sea and their relation to surface water concentrations, Marine Chemistry, 46, 283-292.

Johnson, K.S., and 34 others, 2007. Developing Standards for Dissolved Iron in Seawater, EOS, trans American Geophysical Union, 88, 131. 
Klinkhammer G., P. Rona, M. Greaves, 1985. Hydrothermal manganese plumes in the Mid-Atlantic Ridge rift valley. Nature 314: 727-731.

Lunel T., M. Rudnicki, H. Elderfield, D. Hydes, 1990. Aluminium as a depth-sensitive tracer of entrainment in submarine hydrothermal plumes, Nature, 344, 137-139.

Mackenzie, F.T., M. Stoffyn, R. Wollast, 1978. Aluminum in Seawater: Control by biological activity, Science, 199, 680-682.

McCartney, M.S., S.L. Bennett, M.E. Woodgate-Jones, 1991. Eastward flow through the Mid-Atlantic Ridge at $11^{\prime} \mathrm{N}$ and its influence on the abyss of the Eastern Basin. J. Physical Oceanography, 21: 1089-1121.

Measures, C.I., 1995. The distribution of $\mathrm{Al}$ in the IOC stations of the South and Central Atlantic, Marine Chemistry, 49, 267-281.

Measures, C. I., B. Grant, M. Khadem, D. S. Lee, J. M Edmond, 1984. Distribution of Be, $\mathrm{Al}$, Se and $\mathrm{Bi}$ in the surface waters of the western North Atlantic and Caribbean, Earth Planetary Science Letters, 71, 1-12.

Measures, C.I., J.M. Edmond, T.D. Jickells, 1986. Aluminium in the North West Atlantic, Geochim. et Cosmochim. Acta, 50, 1423-1429.

Measures, C.I. and J.M. Edmond, 1988. Aluminium as a tracer of the deep outflow from the Mediterranean, L. Geophys. Res. 93, 591-595.

Measures, C.I. and J.M.Edmond, 1990. Aluminium in the South Atlantic: steady state distribution of a short residence time element, J. Geophys. Res., 95, 5331-5340.

Measures, C.I. and E.T. Brown, 1996. Estimating dust input to the Atlantic Ocean using surface water Al concentrations, in "The impact of African Dust across the Mediterranean" (Eds. Guerzoni and Chester) Kluwer, 389pp.

Measures, C.I., and S. Vink, 2000. On the use of dissolved aluminium in surface waters to estimate dust deposition to the ocean, Global Biogeochemical Cycles, 14, 317-327.

Measures, C. I., W. M. Landing, M. T. Brown, and C. S. Buck, 2008. High-resolution Al and Fe data from the Atlantic Ocean CLIVAR-CO2 Repeat Hydrography A16N transect: Extensive linkages between atmospheric dust and upper ocean geochemistry, Global Biogeochem. Cycles, 22, GB1005, doi:10.1029/2007GB003042.

Middag, R., H.J.W. de Baar, P. Laan, K. Bakker, 2009. Dissolved aluminium and the silicon cycle in the Arctic Ocean, Marine Chemistry 115, 176-195. 
Middag, R., H.J.W. de Baar, P. Laan, P.H. Cai, and J.C. van Ooijen, 2011. Dissolved manganese in the Atlantic sector of the Southern Ocean. Deep Sea Research Part II 58:2,661-2,677, http:// dx.doi.org/10.1016/j.dsr2.2010.10.043.

Moore, R.M., and G.E. Millward, 1984. Dissolved-particulate interactions of aluminium in ocean water. Geochim. Cosmochim. Acta 48, 235-241.

Moran, S.B., and R.M. Moore, 1991. The potential source of dissolved aluminium from resuspended sediments to the North Atlantic Deep Water. Geochim. Cosmochim. Acta 55, 2475-2751.

Moran, S.B., and R.M. Moore, 1992. Kinetics of the removal of dissolved aluminium by diatoms in seawater: A comparison with thorium. Geochim. Cosmochim. Acta 56, 3365-3374.

Orians, K. J., and K. W. Bruland, 1985. Dissolved aluminum in the central North Pacific, Nature, 316, 427-429.

Orians, K. J., and K. W. Bruland, 1986. The biogeochemistry of aluminum in the Pacific Ocean, Earth Planet. Sci Lett., 78, 397-410.

Resing, J. and C.I. Measures, 1994. Fluorimetric determination of $\mathrm{Al}$ in seawater by FIA with in-line preconcentration, Anal. Chem., 66,4105-4111.

Rona, P. A., 1977. Paleobathymetry if the crest of spreading ridges related to the age of ocean basins-comment, Earth Planet. Sci. Letts., 35, 454-456.

Rudnicki, M.D, and H. Elderfield, 1992. Helium, radon and manganese at the TAG and Snake-pit hydrothermal vent fields, 26-degrees and 23-degrees-n, Mid-Atlantic Ridge, Earth Planet. Sci Letts. 113, 307-321, 1992. doi: 10.1016/0012-821.

Rudnicki, M.D., R.H. James. H. Elderfield, 1994. Near-field variability of the TAG nonbuoyant plume, 26N Mid-Atlantic Ridge, Earth Planet. Sci. Lett. 127.

Schlitzer, R., Ocean Data View, http://odv.awi-bremerhaven.de , 2013.

Siedler, G., Kuhl, A. and Zenk, W., 1987. The Madeira mode water, J. Phys. Oceanogr., 17, 1561-1570, 1987.

Siedler, G., A. Kuhl, and W. Zenk, 1987. The Madeira mode water, J. Phys. Oceanogr., 17, 1561-1570.

Stoffyn, M. and F.T. Mackenzie, 1982. Fate of dissolved Aluminum in the oceans, Marine Chemistry, 11, 105-127. 
Talley, L.D., G.L. Pickard, W.J. Emery, J.H. Swift, 2011. Descriptive Physical Oceanography: An Introduction. $6^{\text {th }} \mathrm{Ed}$, Academic Press, 543pp.

Vink, S. and C.I. Measures, 2001. The role of dust deposition in determining surface water distributions of $\mathrm{Al}$ and Fe in the South West Atlantic, Deep-Sea Research, 48 , 2787-2809.

Worthington, L.V., 1959. The $18^{\circ}$ water in the Sargasso Sea, Deep-Sea Res. 5, 297 305. 


\section{Tables}

Table 1 Hydrothermal vent end member concentrations in the MAR and elsewhere

\begin{tabular}{|l|l|l|l|l|}
\hline Vent site & Si $\mathrm{mM}$ & $\mathrm{Al} \mu \mathrm{M}$ & Fe $\mu \mathrm{M}$ & Si: Al mM: $\mu \mathrm{M}$ \\
\hline Mark 1 & 18.2 & 5.3 & & 3433 \\
\hline Mark 2 & 18.3 & 5.0 & & 3660 \\
\hline TAG & 22 & & 1530 & \\
\hline 21N & 17.5 & 5.2 & 1640 & 3365 \\
\hline Rainbow & $6.3-7.1$ & $1.8-2.9$ & 24000 & $2445-3500$ \\
\hline
\end{tabular}

Table 2 Values used for constructing the mixing series across the MAR

\begin{tabular}{|l|l|l|l|}
\hline Parameter & GT11-12 (AABW) & $\begin{array}{l}\text { GT11-14 Western } \\
\text { flank of MAR }\end{array}$ & $\begin{array}{l}\text { GT11-20 Eastern } \\
\text { Basin }\end{array}$ \\
\hline Si $\mu \mathrm{M}$ & 53.8 & 42.75 & 48.1 \\
\hline $\mathrm{Al} \mathrm{nM}$ & 19.90 & 32.175 & 28.15 \\
\hline
\end{tabular}




\section{Figure captions}

Figure 1. A. Position of the sampling stations during the US GEOTRACES North Atlantic Cruises: Blue 2010, Red 2011 overlaid with the principal surface currents. Inverted diamonds are full depth stations, filled circles are demi stations where sampling was limited to $1500 \mathrm{~m}$.

Figure 2. Distribution of dissolved $\mathrm{Al}$ in the surface mixed layer along the cruise track with the shipboard ADCP $35 \mathrm{~m}$ vectors during station occupation overlaid. Note different Al concentration scale for the expanded section.

Figure 3. Estimations of dust input to the surface waters during the US 2010 and 2011 GEOTRACES cruises and comparison with those estimated for the 2003 A16N CLIVAR cruise.

Figure 4. Dissolved Al distribution (nM) along the USGT10 \& USGT11 cruise tracks. Panels A\&B: upper 1,000 m, overlaid with contours of potential vorticity (10$\left.{ }^{6} \mathrm{~m}^{-2} \mathrm{~s}^{-1} \mathrm{~K} \mathrm{~kg}^{-1}\right)$. Panels $\mathrm{C} \& \mathrm{D}$ : full depth section overlaid with neutral density $\left(\mathrm{kg} \mathrm{m}^{-3}\right.$, panel C) and salinity (panel D).

Figure 5. Correlation between dissolved $\mathrm{Al}$ and salt in the mixing series of Mediterranean Outflow Water and Antarctic Intermediate Water between $\gamma^{v}=27.5$ - $27.9 \mathrm{~kg} \mathrm{~m}^{-3}$. The large cross at $72 \mathrm{nM} \mathrm{Al}$ is the concentration of dissolved $\mathrm{Al}$ in the MOW outflow reported by Measures and Edmond, 1998, the small box at $2.5 \mathrm{nM}$ is the value reported by Measures, 1995 for AAIW.

Figure 6. Concentration of dissolved Al at USGT11-14, 16 \&18 (in colour) showing the hydrothermal plume. All samples were collected with the GT rosette system except for USGT11-16 SIO (red), which were collected with the normal hydrographic rosette. Black circles are all the dissolved $\mathrm{Al}$ concentrations in the USGT11 and USGT10 zonal sections.

Figure 7. Dissolved $\mathrm{Al}$ and Si correlation plot demonstrating the feasibility of producing eastern basin water with characteristic dissolved $\mathrm{Al}$ and $\mathrm{Si}$, such as seen at USGT11-20 by mixing of Al enriched Lower North Atlantic Deep Water sampled at USGT11-14 with Si enriched Antarctic Bottom Water sampled at the USGT11-12 as they pass through the Vema Fracture Zone.

Figure 8. A. Dissolved $\mathrm{Al}$ in the Mauritanian section overlain with $\mathrm{O}_{2}$ concentrations.

B. The ratio of dissolved $\mathrm{Si}$ to $\mathrm{Al}$ in the Mauritanian section, overlain with $\mathrm{O}_{2}$ concentrations. 
мә!^ еұеg иеәэо

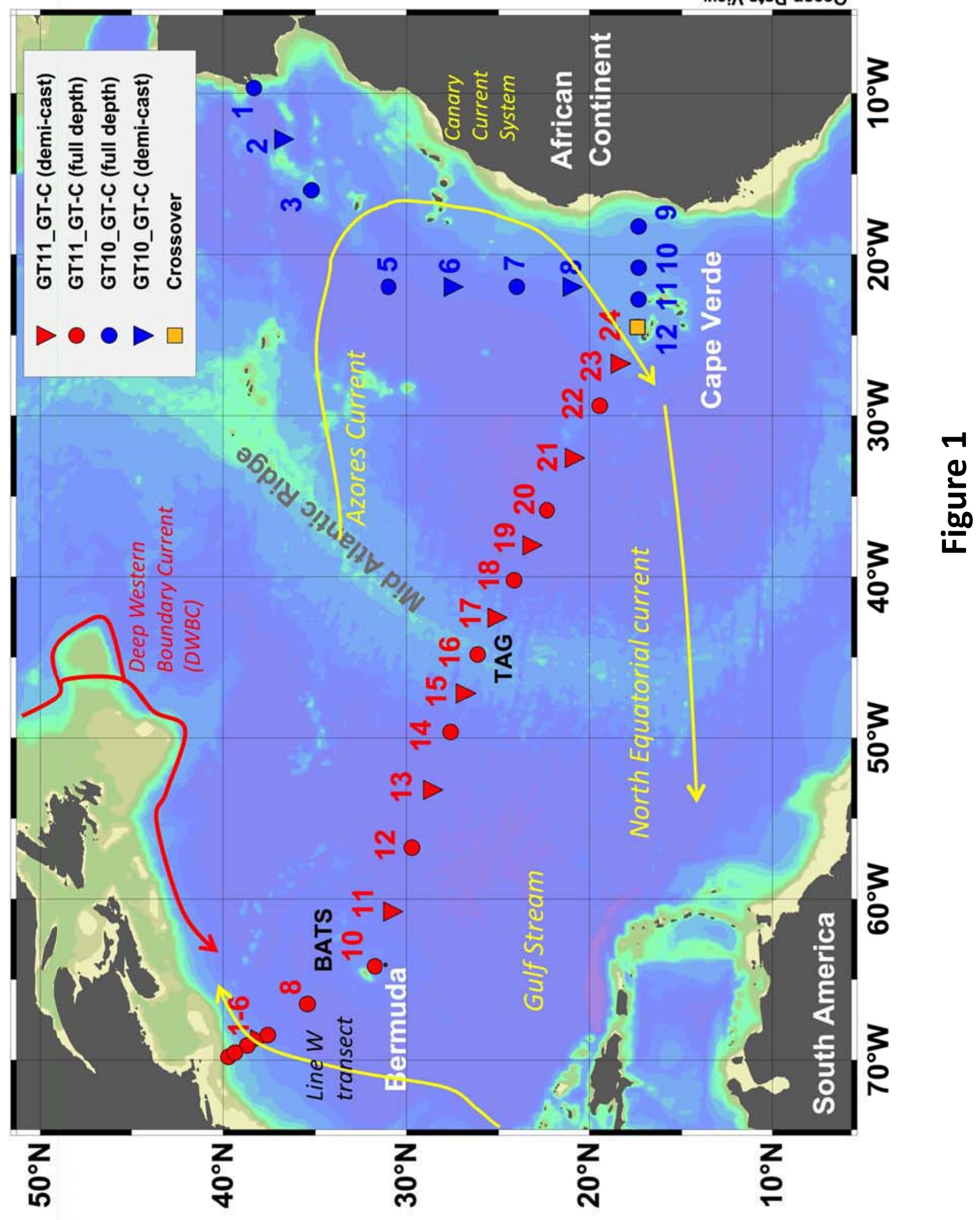


ถึ

ㅇ

ర్లి

กิ

우

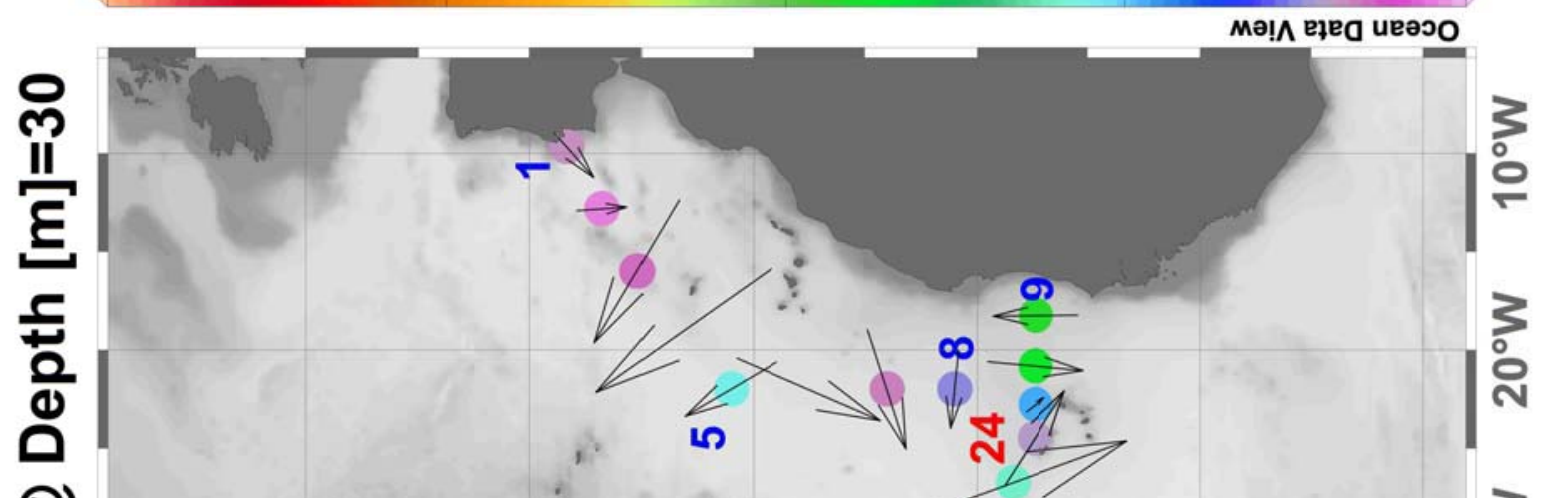

()
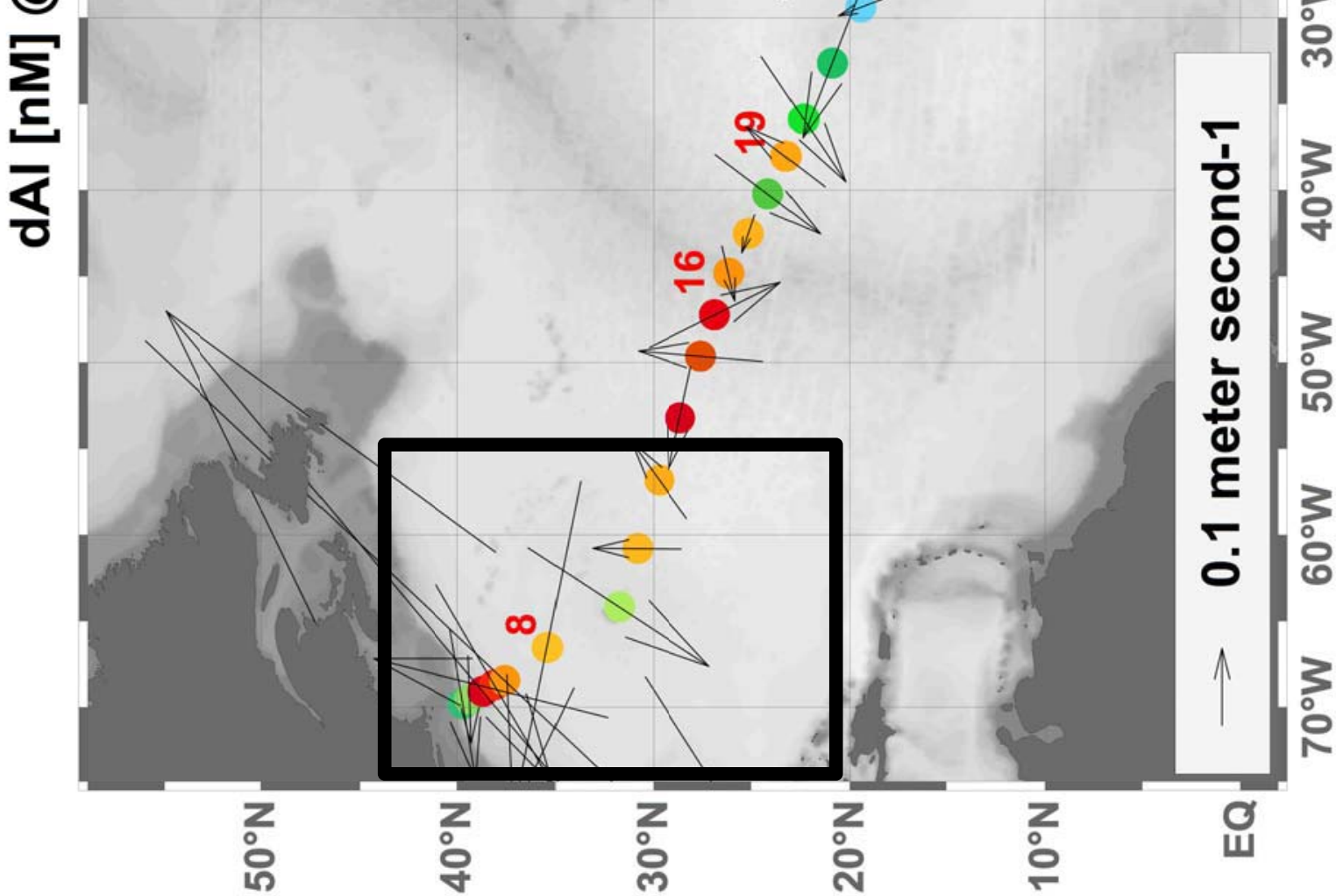

N
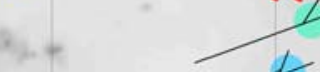

3.

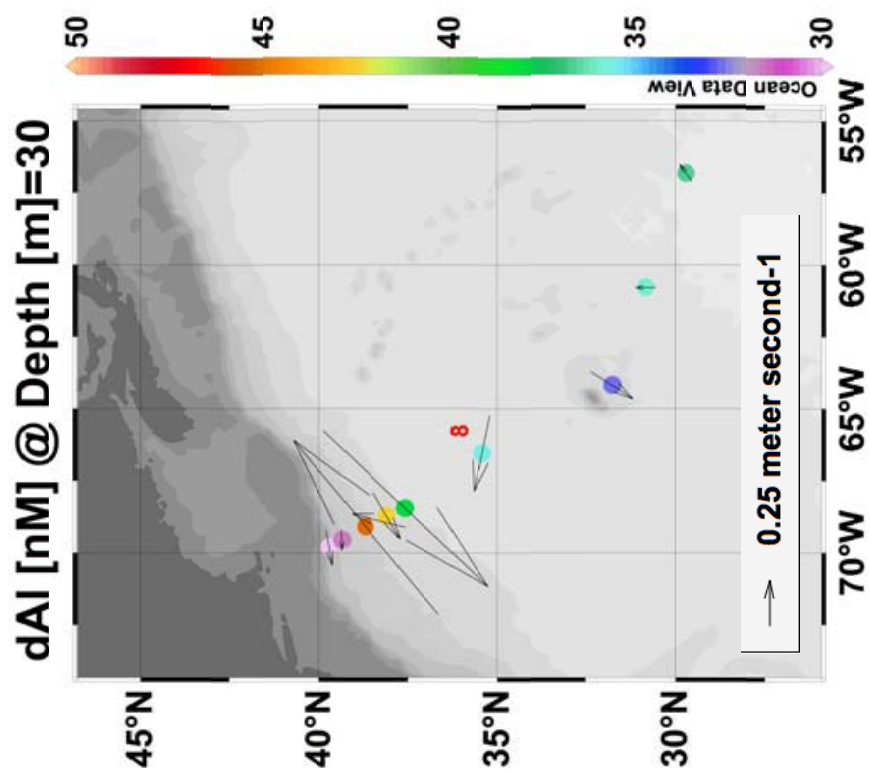




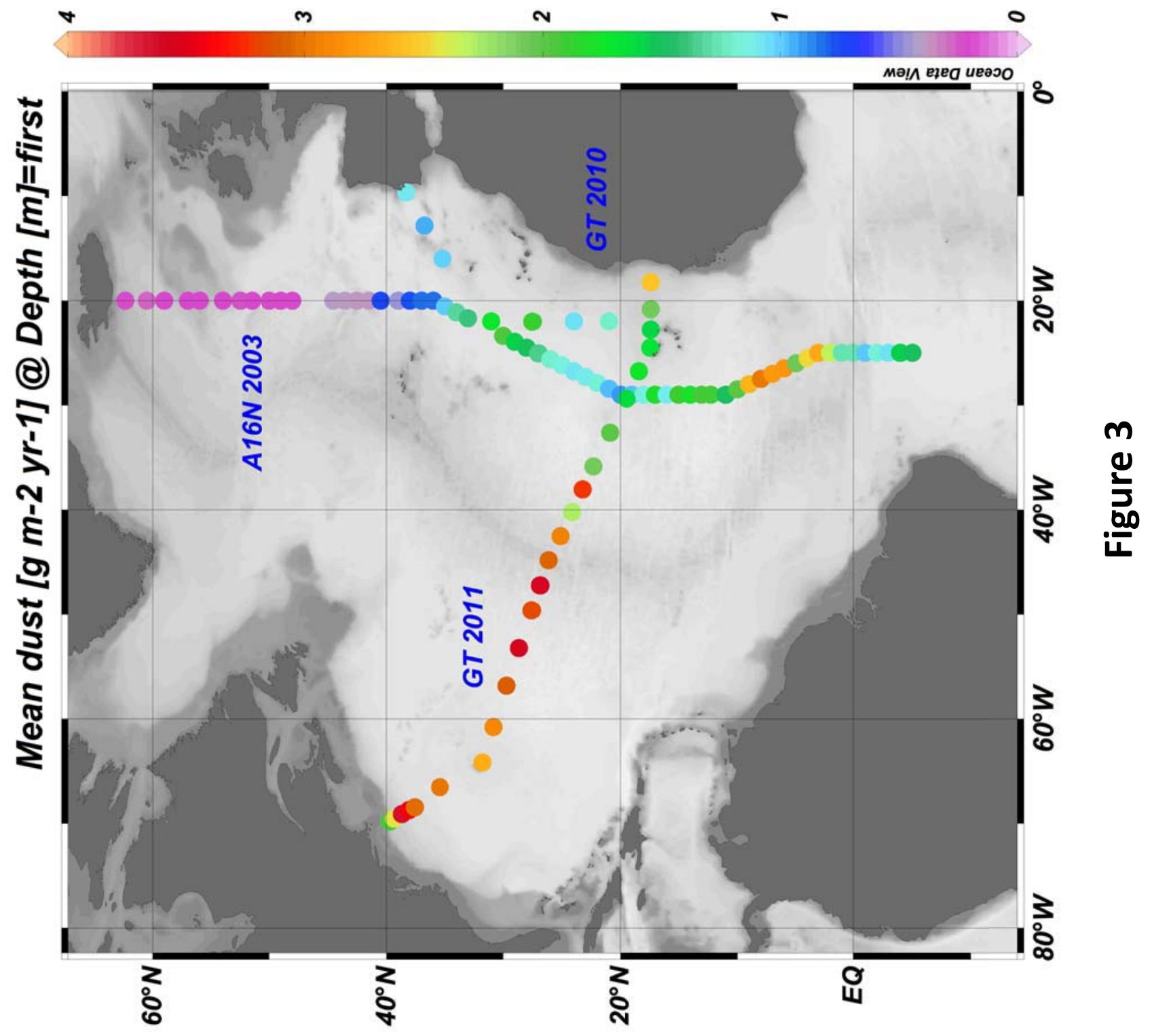




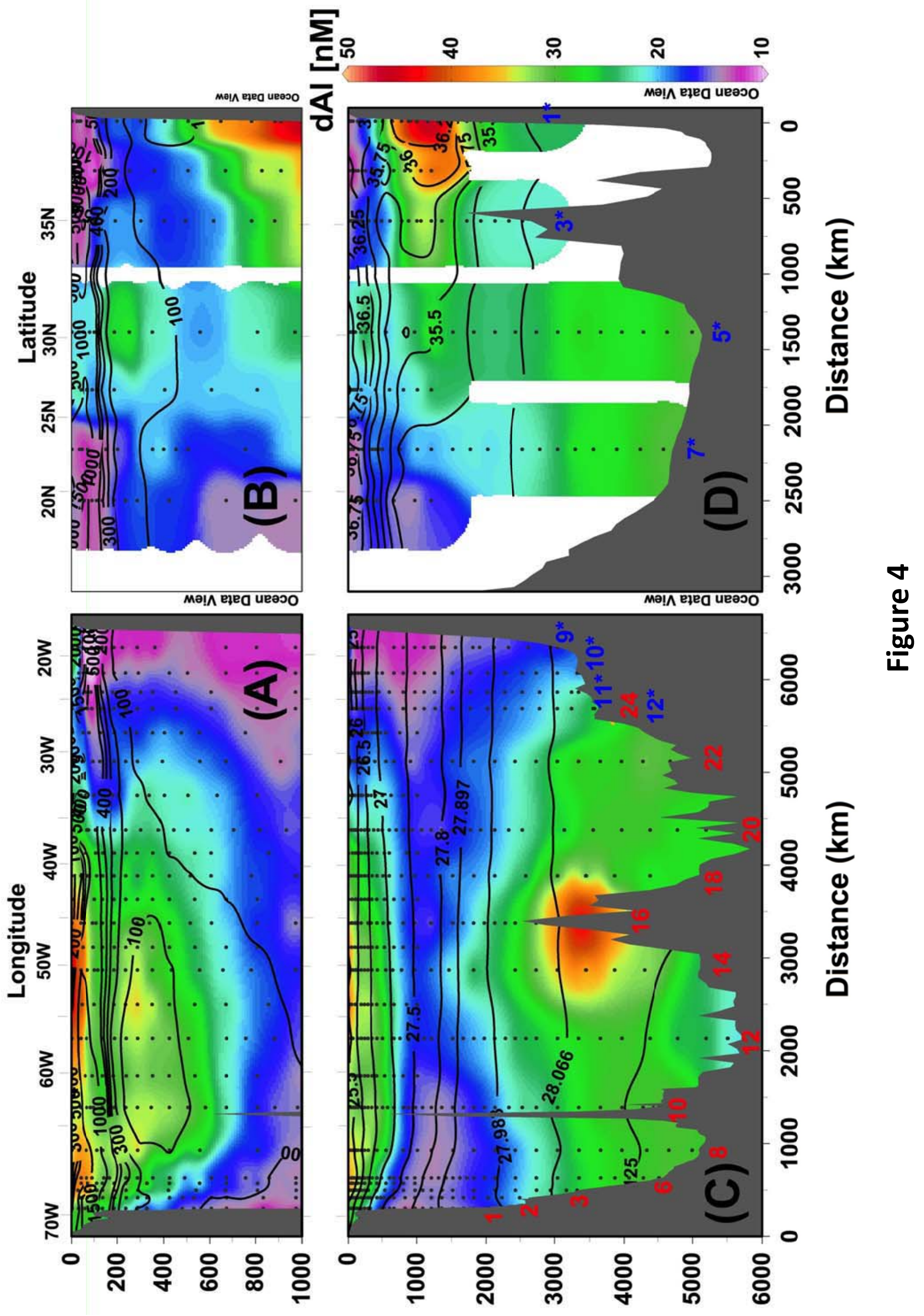




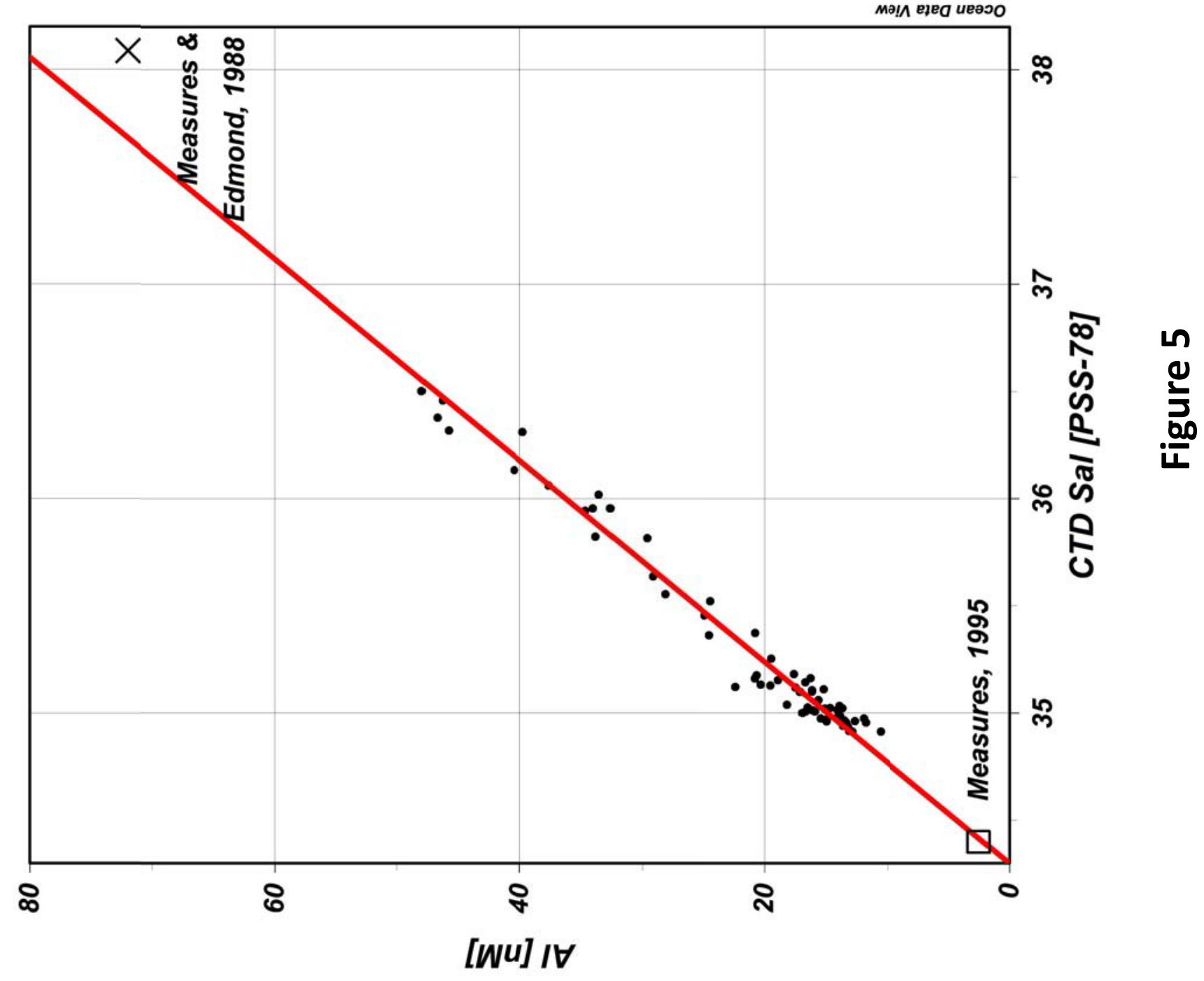




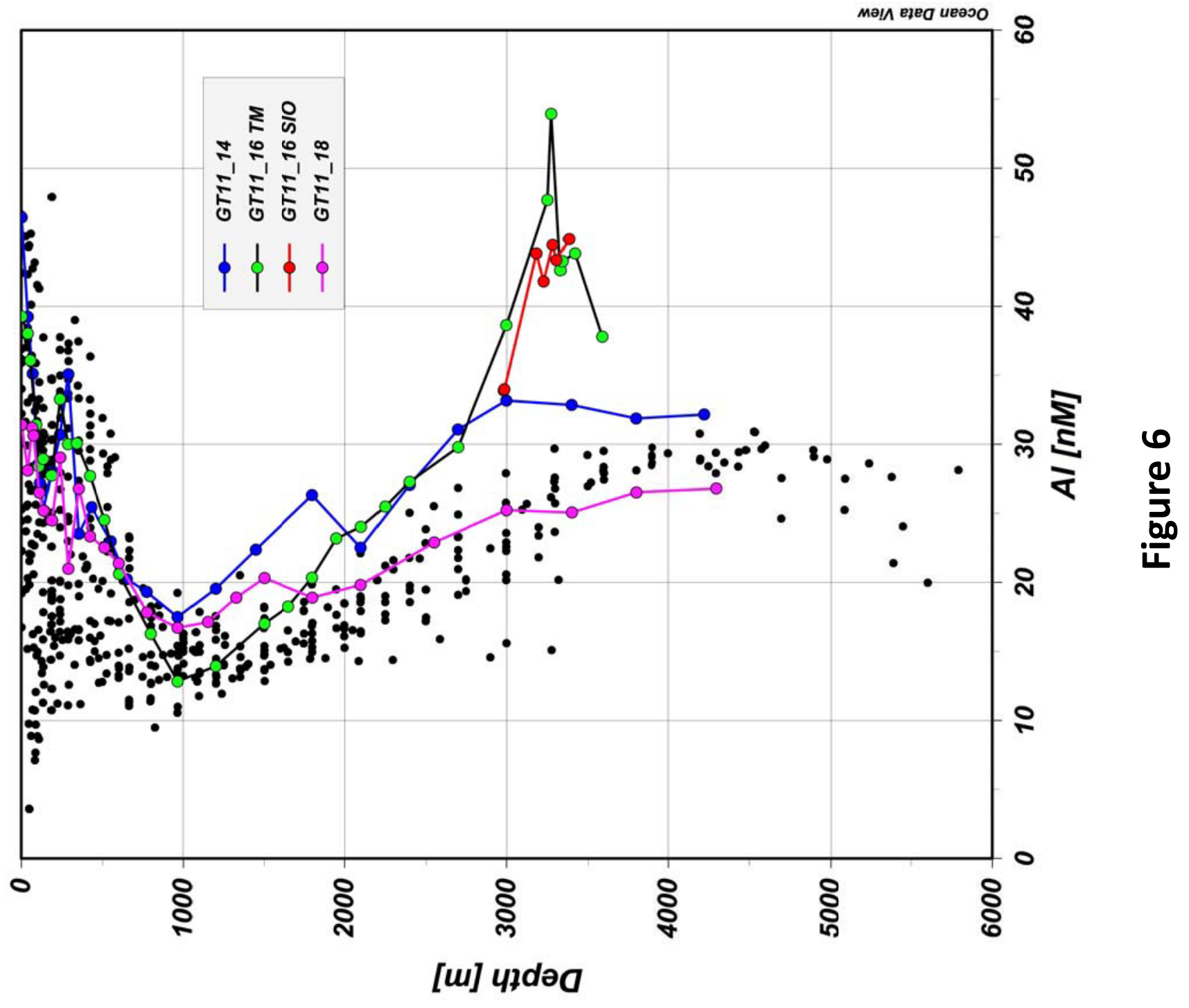




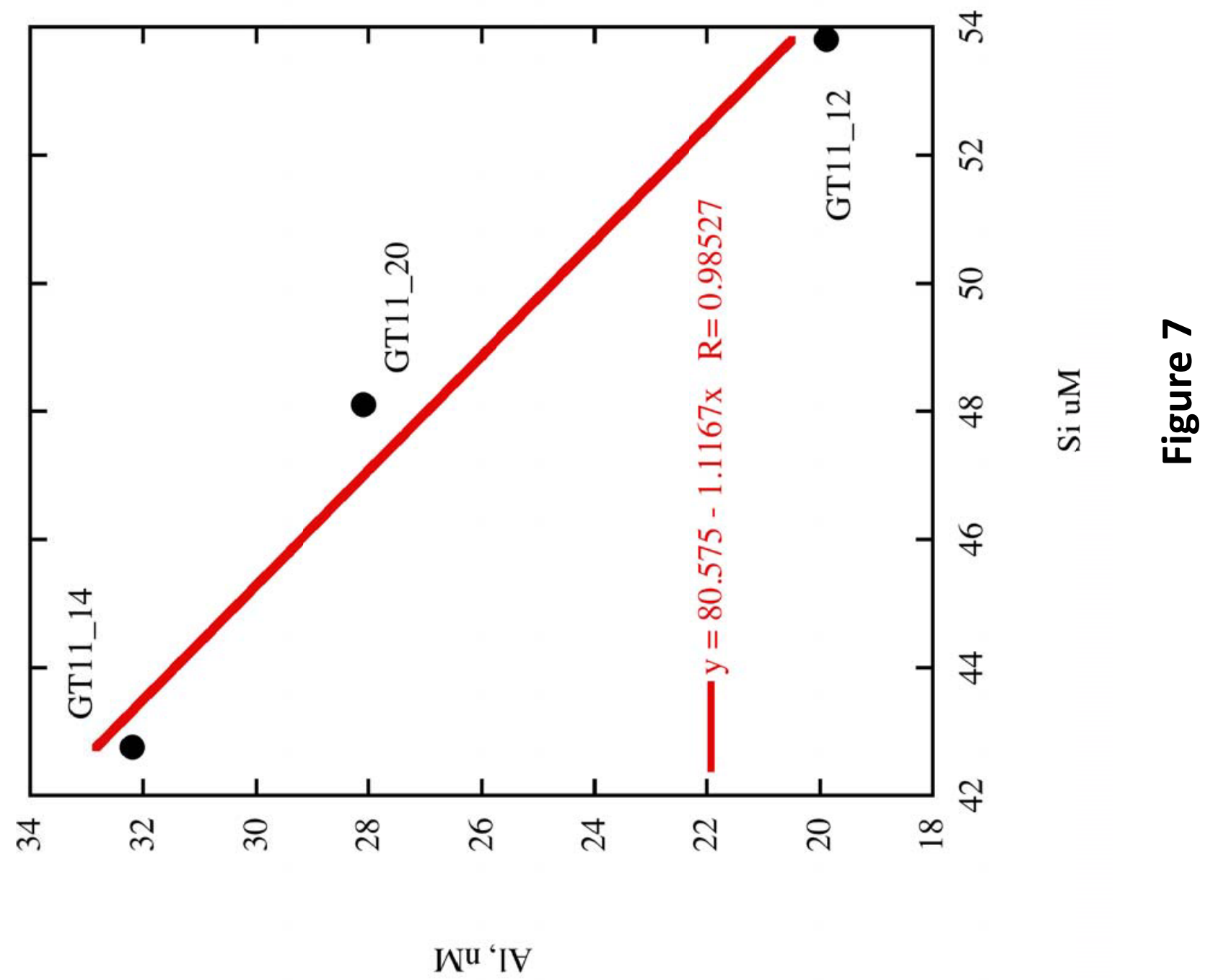



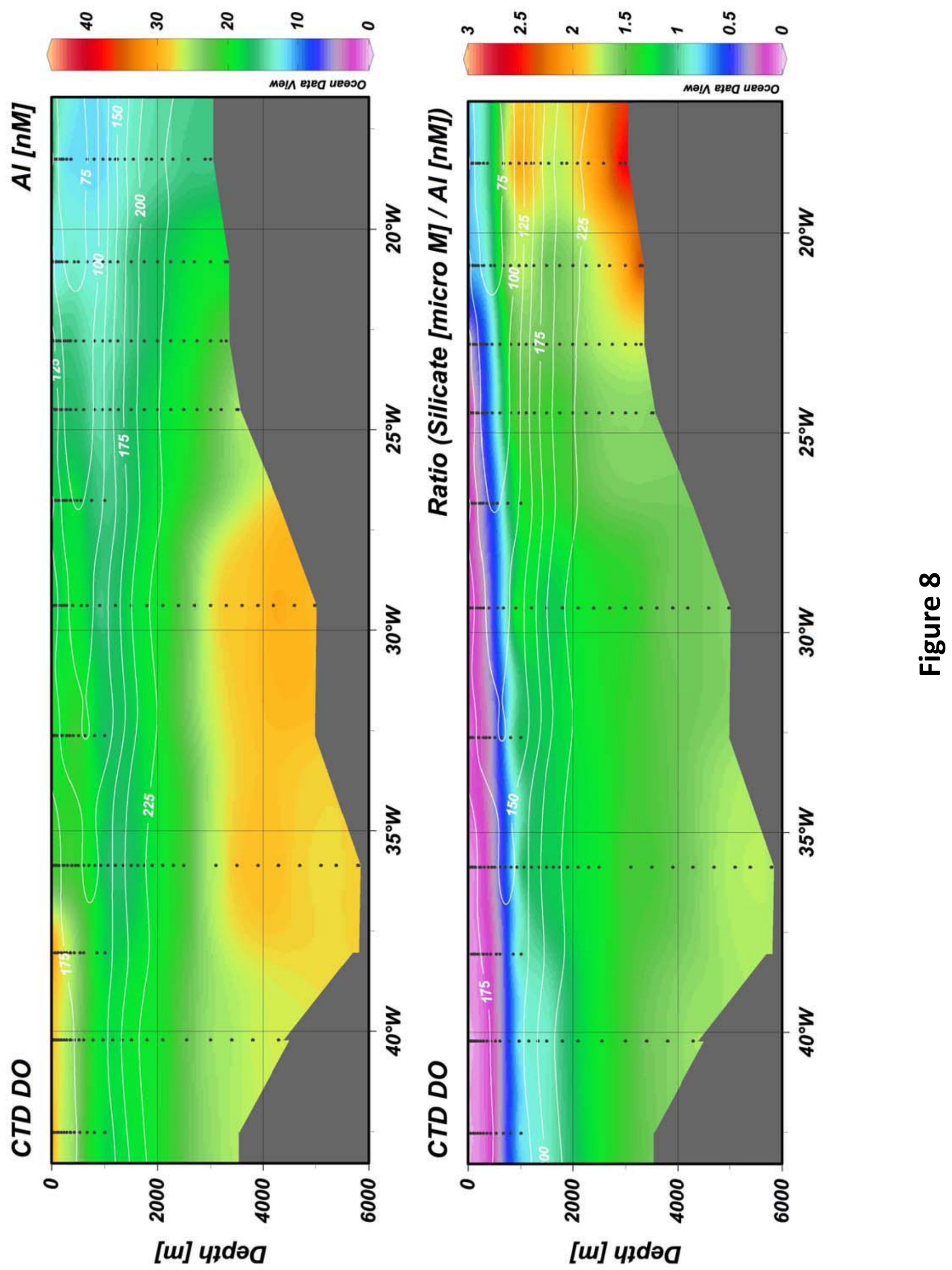